\title{
Vulnerability Assessment of Farmer's Livelihood to Climate Change a Case Study of farmers in Logo Anseba District, Eritrea
}

\author{
Dawit Tesfai, Zhang Jing \\ Engineering. Tongji University, Shanghai 200092, P.R. China. \\ DOI: 10.29322/IJSRP.10.05.2020.p10154 \\ http://dx.doi.org/10.29322/IJSRP.10.05.2020.p10154
}

Tongji University, UN Environment-Tongji Institute of Environment for Sustainable Development (IESD): College of Environmental Science and

\begin{abstract}
Eritrea is among the most vulnerable group of countries to the adverse effects of climate change, mainly because of its low adaptive capacity and its semi-arid and arid climate conditions. To assess the climate change impact and associated vulnerability for the Debri and Liban communities in the Logo Anseba district of Eritrea a comparative analysis of livelihood vulnerability index (LVI) was computed. Analysis of relative LVI based on the household's survey shows that farming households in Liban community were more vulnerable to climate change and variability especially in terms of water, food and health sub component indicators. The overall LVI calculated revealed that Liban households were found vulnerable to climate change and variability with LVI value of 0.450 as compared to Debri households with 0.388 .
\end{abstract}

Index Terms- Climate change, community, Logo Anseba, vulnerability

\section{INTRODUCTION}

$\mathrm{T}$ he adverse effect of climate change and variability has become an environmental and socio-economic problem which is increasingly causing climate-driven hazards to people around the world [1]. Climate change and related disasters occur worldwide but have particularly severe effects on agriculture in the developing world, having a negative impact on food production [2,3]. Climate change poses new challenges to agriculture and society in general, in particular regarding land use and the supply of food.[4]

Across the tropics, smallholder farmers already face numerous risks to their agricultural production, including pest and disease outbreaks, extreme weather events and market shocks, among others, which often undermine their household food and income security $[3,5]$. Because smallholder farmers typically depend directly on agriculture for their livelihoods and have limited resources and capacity to cope with shocks, any reductions to agricultural productivity can have significant impacts on their food security, nutrition, income and well-being [6, 7].

The fifth IPCC Assessment Report indicated that human induced climate change scenarios project warming of $4-7^{\circ} \mathrm{C}$ (on average) over much of the global landmass by the end of the 21st century. [8] Global sea level rise 9 to $88 \mathrm{~cm}$ and CO2 concentration 478 to $1099 \mathrm{ppm}$ based on the projections by 2100 as compared to 1990[9].

Based on the IPCC $4^{\text {th }}$ assessment report, in Eritrea, mean annual temperatures have increased by $1.7^{\circ} \mathrm{C}$ since 1960 , an increase of $0.37^{\circ} \mathrm{C}$ per decade; higher than the global average of $0.13^{\circ} \mathrm{C}$ increase per decade. $\mathrm{CO} 2$ emissions has made a limited contribution to climate change with $0.1 \mathrm{t} /$ person/year to date but evidence shows that the effects of climate change are being felt in Eritrea. Seasonality of rainfall is changing with the early rainy season (April-mid-June) shortening or not occurring and main wet season ending in August rather than September [10]. Government report indicated that from 1900-2000 the summer rainy season had shortened from 5 months to 2.5 months [11]

In Eritrea Climate change is a major challenge to achieving household and national food security and to the alleviation of poverty. Eritrea is one of the poorest and food insecure countries in the world: of the population of 4.5 million, $66 \%$ of the population were undernourished and 37\% lives in extreme poverty [12]. More than $70 \%$ of the national population is dependent on agriculture, livestock or fisheries: in term of employment and food security, agriculture is the mainstay of the Eritrean economy - smallholder agriculture accounts for $95 \%$ of total agricultural production and rain fed agriculture, despite very low yields, is the main source of staple foods (maize, sorghum, pearl millet, wheat, barley). Nevertheless, agricultural sector has a share of only $14 \%$ of GDP: most agriculture is in fact carried out using traditional crop varieties and simple technologies with limited use of improved seeds or inorganic fertilizers and or mechanization.[13]

Eritrea is situated in sub-Saharan Africa whose climate regime is highly variable being influenced by the expanding Sahlo-Saharan desert, the proximity to the Red Sea and the physical features or topography of the land. Altitude and physical features play a major role in determining climate in general and temperature in particular. Mean annual temperature falls by approximately $1^{\circ} \mathrm{C}$ for each 200 meters 
rise in elevation.[14] The harvest depends highly the amount on rainfall. Scarcity of rain, therefore, leads to food insecurity. Agriculture and pastoralism are the main source of livelihood for about 80 percent of Eritrea population. [15].

Eritrea is among the most vulnerable groups of countries to the adverse effects of climate change, mainly because of its low adaptive capacity and its semi-arid and arid climate conditions.[16] Vulnerability assessment describes a diverse set of methods used to systematically integrate and examine interactions between humans and their physical and social surroundings.[17].

Past studies on vulnerability in Eritrea have mostly been focused on national sub-sectoral level of climate change impact on socioeconomic impact.[14] most studies tried to measure vulnerability by using State-Pressure-Impact-Adaptation model which is a more appropriate approach to assess the climate change impacts and vulnerability on the main socio-economic sectors and the populations dependent on it. This model allows a logical sequence of cause and effect analysis of what is happening and what may happen due to climate change and it measured vulnerability to extreme climatic events using national aggregates without household level data. [14].

our study is therefore intended to fill the aforementioned gap by employing household data to analyze farmers' vulnerability to climate change and variability using the livelihood vulnerability Index (LVI) frameworks approach to understand vulnerability to climate change as it provides a basis for investigating both the key components that make up livelihoods and the contextual factors that influence them. The LVI is designed to provide development organizations, policy makers, and public health practitioners with a practical tool to understand demographic, social, and health factors contributing to climate vulnerability at the community or community level[18]. This study is opted to assess level of livelihood influenced by climate change and variability using relative of LVI valuation of the households. Because the adaptive capacity of the community is, dependent upon the resources of the region. Adaptive capacity of a local area in turn is determined by politics, culture, economics, environment and other conditions. [19] [20] Local ability to adapt can be influenced by the way resources are managed and the financial, technical and information resources of the community and region [21, 22]

\section{METHODS}

\section{Study area description}

Sub region Logo Anseba is a sub region in the western part of Gash Barka of Eritrea. The sub region is bordered by the Anseba, Maekel and Debub regions. It has an altitude between 1600-2400 meters above sea level, with a semi-arid climate. The total population of Logo Anseba is 33,446; it is composed of 13 local administrative sites, and 22 villages. Most of the inhabitants of Logo Anseba live by farming, cultivating wheat, sorghum, finger millet and pulses. During the dry season from November to March, the inhabitants perform other work such as trade and construction. Logo Anseba is the origin for one of the main rivers, the Barka River, which flows all the way into Sudan [23]. Owing to the characteristics of topography and climatic variations, Logo Anseba is one of severely vulnerable part of the country. Most of the inhabitants of Logo Anseba live by farming, cultivating wheat, sorghum, finger millet and pulses. During the dry season from November to March, the inhabitants perform other work such as trade and construction.

\section{Data Collection}

The study employed both primary and secondary data. The primary data was collected from the farming households in Debri and Liban communities in the Logo Anseba communities in Eritrea. The primary data was gathered through field survey of randomly selected households. Based on a sample size calculation with finite population. For the household survey 215 respondents were selected. The field survey was carried out by disseminating a combination of an open and closed structured questionnaire as well as interview. The questionnaire was first discussed with the technical staff of the Ministry of Agriculture in the region and later used to interview the selected respondents in both Debri and Liban communities. A secondary data was also collected from the Ministry of Agriculture of Logo Anseba sub region branch on the precipitation and temperature over a period of 2009-2018. This statistical data was used to assess vulnerability due natural disasters and variability which is one of the components indicators used to calculate farmer's livelihood vulnerability index (LVI). Different documents regarding adaptation policies and sectoral vulnerability assessment was also collected.

\section{Calculation of LVI}

In demonstrating the vulnerability of the farming households in Logo Anseba Sub region to climate change and variability a balanced weighted approach was used to compute the livelihood vulnerability index (LVI) which was developed by Hahn et al (2009)[18].

The Livelihood Vulnerability context is important to understand vulnerability to climate change because it provides a basis for investigating both the key components that make up livelihoods and the contextual factors that influence them. For the livelihood vulnerability assessment of Debri and Liban communities the LVI calculation includes eight major components: Socio-demographic profile, Livelihood strategies, Social networks, water, Health, Food, Production and Natural Disasters and Climate Variability. Each major component contains several sub component which are indicators for household's livelihood. Since the sub component are the result of different scales it needs to be standardized as an index using equation (1) and make ready for LVI calculation of each component (see Appendix A)

$$
\operatorname{Index} S_{d i}=\frac{S_{c}-S_{\min }}{S_{\max }-S_{\min }}
$$


Where $S_{\mathrm{di}}$ is the observed value of sub component for community d, S min and $\mathrm{S}$ max are minimum and maximum values respectively of each sub component determined from the households in each community.

After each observed sub component value is standardized, it needs to be averaged using equation (2) to find the induces of each major component

$$
M_{d i}=\frac{\sum_{i=1}^{n} \text { index } s_{d i}}{n}
$$

Where $\mathrm{M}_{\mathrm{d}}$ is one of the eight major components for community d [Socio-demographic profile (SDP), Livelihood strategies (LS), Social networks (SN), water (W), Health (H), Food(F), Production (P) and Natural Disasters and Climate Variability (NDCV)], index $\mathrm{S}_{\mathrm{di}}$ represents the indexed sub-components values and $\mathrm{n}$ is the number of sub-components in each major component.

When the value of each of the eight major components for both communities were calculated then they were averaged using equation 3 to get the communities level of livelihood vulnerability index (LVI) Table 3

$$
L V I_{h}=\frac{\sum_{n=1}^{n} W_{M_{i}} M d_{i}}{\sum_{i=1}^{8} W M_{i}}
$$

Which is expressed as;

$$
L V I_{h}=\frac{w_{S D P} S D P_{d}+w_{L S} L S_{d}+w_{S N} S N_{d}+w_{W} W_{d}+w_{H} H_{d}+w_{F} F_{d}+w_{P} P_{d}+w_{N D C V} N D C V_{d}}{w_{S D P}+w_{L S}+w_{S N}+w_{W}+w_{H}+w_{F}+w_{P}+w_{N D C V}}
$$

where $\mathrm{LVI}_{\mathrm{h}}$, the Livelihood Vulnerability Index for community d, equals the weighted average of the eight major components. The weights of each major component, $\mathrm{W}_{\mathrm{Mi}}$, are determined by the number of sub-components that make up each major component and are included to ensure that all sub-components contribute equally to the overall LVI [18] . In this study, the LVI is scaled from 0 (least vulnerable) to 0.8 (most vulnerable). For illustrative purposes, a detailed example of calculating the Natural Disaster and climatic variability (NDCV) major component for the LVI for one of the Debri community is presented in Appendix A.

\section{IPCC Framework for Calculating LVI}

The alternative method for calculating LVI incorporated the IPCC vulnerability definition by grouping all major components under exposure, adaptive capacity, and sensitivity taken as contributing factors for livelihood vulnerability to climate change and variability. Each major component comprised several subcomponents or indicators, the same as in the LVI. (see Appendix B)

Similar to LVI, equations (1) - (4) were also used to calculate the LVI-IPCC. However Instead of using one weighted average, this method calculated three weighted averages of the major sub-components according to the three contributing factors as explained using equation (5):

$$
C F_{d}=\frac{\sum_{i=1}^{n} W_{M_{i}} M_{d_{i}}}{\sum_{i=1}^{n} W_{M_{i}}}
$$

where $\mathrm{CF}_{\mathrm{d}}$ is an IPCC-defined contributing factor (exposure, sensitivity, or adaptive capacity) for community $\mathrm{d}$, $\mathrm{M}_{\mathrm{di}}$ are the major components for community d indexed by $\mathrm{i}, \mathrm{W}_{\mathrm{Mi}}$ is the weight of each major component, and $\mathrm{n}$ is the number of major components in each contributing factor. Once exposure, sensitivity, and adaptive capacity were calculated, the three contributing factors were combined using equation (6)

$$
\mathbf{L V I}-\mathbf{I P C C}=\left(\mathbf{e}_{\mathbf{d}}-\mathbf{a}_{\mathbf{d}}\right) * \mathbf{S}_{\mathbf{d}}
$$

where $e_{d}$ is the calculated exposure score for community d (equivalent to the Natural Disaster and Climate Variability major component), a is the calculated adaptive capacity score for community d (weighted average of the Socio-Demographic, Livelihood Strategies, and Social Networks major components), and $S$ is the calculated sensitivity score for community d (weighted average of the Heath, Food, and Water major components) (Table 2). For illustrative purposes, a detailed example of calculating LVI-IPCC of Liban community is presented in Appendix D.

\section{LVI: Debri versus Liban}

\section{RESUlT AND DISCUSSION}

The major components and the composite LVI for each community are presented in Table 3. The results revealed that the vulnerability indices of the major component ranged from 0.10 to 0.758 . In the vulnerability index of the socio-demographic profile 
component of the LVI the result showed that the dependency ratio was higher for Debri (0.152) than Liban (0.138). However, Liban Showed grater vulnerability (0.435) on the socio-demographic profile index than Debri (0.428). This could be due to the fact that the population proportion $<15$ and $>65$ years members of the household family is relatively grater in Debri than Liban. About $73.4 \%$ of the household heads in both communities had no any formal educational background. Even though formal education obtained by the smallholder farmers is sought to play an important role to better realize possible solutions for different climate related calamities, the indigenous knowledge coupled with the various training and extension services make a difference to the vulnerability of climate stresses. Average reported age of Debri female household heads was $46.1 \pm 10$ years as compared to $47 \pm 7$ years in Liban.

The second major component was the livelihood strategy which is composed of three sub-component indicators. The Liban community showed greater vulnerability (0.582) founded from the average agricultural livelihood diversification index than Debri (0.391). This indicates that the Debri community are involved in more agricultural livelihood activities. When the value of the sub components in the livelihood strategy were aggregated Liban showed grater vulnerability (0.558) than did Debri (0.535). Based on the percentage of households with family members working in different communities, Liban showed grater vulnerability (0.433) than Debri (0.318). This signifies that more households in Liban have more family members working in other communities than Debri which is $43.3 \%$ and $31.8 \%$ respectively. The Debri community have higher percentage of households dependent solely on agriculture as a source of income $(89.5 \%)$ as compared to Liban which is $(65.8 \%)$. This could be due to the fact that Debri have a better agronomic practices and relatively well agricultural infrastructures such as dams. This means Debri community are less likely to be vulnerable to potential climatic stresses because they are involved in many diversified agricultural activities which have twofold benefits, as a source of income and as a means easing for adoption of climate change strategy.

\section{Major Components Sub components}

Socio-demographic profile

Livelihood strategies

Social networks

water

Health

Food

Production

Dependency ratio attended school source of income

supply

household food
Percent of female-headed households

Average age of female-head of household

Percent of households where head of household has not

Percent of households with family member working in a different community

Percent of households dependent solely on agriculture as a

Average agricultural livelihood diversification index

Average receive: give ratio

Average borrow: lend money ratio

Percent of households that have not gone to their local

government for assistance in the past 12 months

Percent of households reporting water conflicts

Percent of households that utilize a natural water source

Average time to water source

Percent of households that do not have a consistent water

Inverse of the average number of liters of water stored per

Average time to health facility in min. (on foot)

Percent of households with family member with chronic illness

Percent of households where a family member had to miss

work or school in the past 6 months due to illness

Average malaria exposure*prevention index

Percent of households dependent solely on the family farm for

Average number of months households struggle to find food

Percent of households that do not save crops

Percent of households that do not save seeds

Average Crop Diversity Index

Percent of households that use drought resistant crop varieties to adapt climate change

\begin{tabular}{|c|c|c|c|}
\hline \multicolumn{2}{|c|}{ Composite value } & \multicolumn{2}{|c|}{ Index value } \\
\hline Debri & Liban & Debri & Liban \\
\hline 0.152 & 0.138 & 0.438 & 0.435 \\
\hline 0.179 & 0.183 & & \\
\hline 0.725 & 0.647 & & \\
\hline 0.695 & 0.77 & & \\
\hline 0.831 & 0.975 & 0.706 & 0.738 \\
\hline 0.895 & 0.658 & & \\
\hline 0.391 & 0.582 & & \\
\hline 0.226 & 0.214 & 0.735 & 0.721 \\
\hline 1 & 1 & & \\
\hline 0.98 & 0.95 & & \\
\hline 0.11 & 0.8 & 0.299 & 0.461 \\
\hline 0.9 & 0.45 & & \\
\hline 0.063 & 0.57 & & \\
\hline 0.211 & 0.41 & & \\
\hline 0.211 & 0.079 & & \\
\hline 0.12 & 0.073 & 0.100 & 0.164 \\
\hline 0.095 & 0.091 & & \\
\hline 0.073 & 0.067 & & \\
\hline 0.112 & 0.26 & & \\
\hline 0.842 & 0.975 & 0.243 & 0.343 \\
\hline 0.186 & 0.435 & & \\
\hline 0.063 & 0.1 & & \\
\hline 0.053 & 0.042 & & \\
\hline 0.070 & 0.163 & & \\
\hline 0.821 & 0.692 & 0.758 & 0.730 \\
\hline
\end{tabular}


Percentage of household facing problems related to climate change before and/or after harvesting the produce(pest/weed/disease)

Natural Disasters and Climate Variability pending natural disasters since last 6 years
Percent of households that did not receive a warning about the

Percent of households with an injury or death as a result of flood or drought since last 6years

Mean standard deviation of monthly average of average

maximum daily temperature (2009-2018)

Mean standard deviation of monthly average of average minimum daily temperature (2009-2018)

Mean standard deviation of monthly average precipitation (2009-2018)
$0.694 \quad 0.767$

$\begin{array}{llll}0.832 & 0.917 & 0.386 & 0.435\end{array}$

$0.021 \quad 0.092$

$0.321 \quad 0.357$

$0.455 \quad 0.491$

$0.302 \quad 0.317$

\section{Overall LVI \\ Table 3 Indexed sub-components, major components, and overall LVI for Debri and Liban Communities, Eritrea

The third major component was social networks which consisted of three sub components. The result of the Social networks indicators has showed similarities in both communities. Despite the fact that there is a tradition of helping each other in the communities, the household respondents in both communities reported that they have not borrowed or lent money among themselves in the given onemonth time. The result also showed that the Percent of households that have not gone to their local government for assistance in the past 12 months was $98 \%$ and $95 \%$ in Debri and Liban respectively. When the sub components in the social networks were aggregated, the result showed Liban households was to some extent vulnerable (0.728) than Debri households (0.725). Lately Debri community has made an attempt to organize themselves into cooperatives, producer groups and different community development groups through which help would be shared among themselves.

The fourth major component was water which consisted five sub components. The overall vulnerability index of the water component indicate that Liban was vulnerable (0.481) than Debri $(0.299)$. The percentage of household reporting water conflict in their community showed Liban was more vulnerable (0.8) than Debri households (0.11). With respect to utilization of natural water sources such as rivers and lakes Debri showed greater vulnerability (90\%) than Liban (55\%). The LVI vulnerability also showed that Liban scored high vulnerability (0.42) for the percent of households that do not have a consistent water supply than Debri (0.211). In Debri the community constructed two dams one with the help of the government and one through contribution by the community members in and outside the country. As a result, Debri reported minimum average travelling time $33.8 \pm 17$ minutes to the water source as compared to Liban $64.1 \pm$ minutes. Consequently, Liban store more average number of liters of water per household $200 \pm 150$ liters than average number of liters of water per household in Debri $120 \pm 80$ liters.

The fifth major component was health which comprise four sub component indicators namely, average time to health facility in minutes (on foot), Percent of households with family member with chronic illness, Percent of households where a family member had to miss work or school in the past 6 months due to illness and average malaria exposure prevention index. The vulnerability index of the health component of the LVI showed that Liban households was more vulnerable (0.164) than Debri (0.1). However, based on the indicator of average time to health facility Debri showed more vulnerability $(0.12)$ than Liban $(0.073)$. The percentage of households where a family member had to miss work school or work in the last six months was slightly greater for Debri (9.3\%) than Liban (6.7\%). With regard to the percentage of household with chronic illness in the family the result showed similar value $9.5 \%$ and $9.1 \%$ for Debri and Liban respectively.

The sixth major component was food comprising five sub component. Based on the percent of households dependent solely on the family farm for food, Liban was more vulnerable (0.975) than Debri (0.842). Average number of months households struggling to find food is greater for Liban 5.22 months than Debri 2.53 months. In Debri 2 ha land was allocated for every member of the community for crop and vegetable production using drip irrigation from the constructed dams. The average crop diversity index showed that Liban was more vulnerable (0.163) than Debri $(0.070)$. when the sub component indicators were aggregated Liban showed more vulnerability (0.349) as compared to Debri (0.386). higher value of vulnerability was recorded for the percent of storing crop and seed in Liban (10\% and 6.3\%) than Debri (6.3\% and 5.3\%) respectively.

The seventh major component was production which comprise two sub component indicators. The percent of households that use drought resistant crop variety to adapt the changing climate was greater in Debri with index 0.821 as compared to Liban households 0.692.with regard to percent of households facing problems related to climate stress before and/or after harvest such as weed pest infestation and diseases, Liban recorded greater vulnerability index (0.767) than did Debri (0.694). Crop production is highly sensitive to climate. It is affected by long-term trends in average rainfall and temperature, interannual climate variability, shocks during specific phenological stages, and extreme weather events (IPCC, 2012). Some crops are more tolerant than others to certain types of stresses, and at each phenological stage, different types of stresses affect each crop species in different way[24]. As climate changes, crop production strategies must change too. Overall, the result showed that Liban recorded more production vulnerability $(0.771)$ than Debri (0.740)

The eighth major component was natural disaster and climate variability which consist five sub component indicators. when all the subcomponent indexes were aggregated Liban showed more vulnerable $(0.410)$ to natural disasters and climatic variability than did 
Debri (0.386). The percent of households that do not receive a warning about the pending natural disaster in 6-year time was high in both communities with indices 0.83 for Debri and 0.85 for Liban. This signifies that the early warning system in the country is a weak. Vulnerability index value recorded for Debri and Liban with regard to the mean standard deviation of monthly average precipitation (for 2009-2018) were 0.302 and 0.314 respectively. Mean standard deviation of monthly average of average maximum daily temperature (2009-2018) for Debri and Liban were $(0.327,0.357)$ and minimum $(0.455,0.491)$ respectively.

The result of this study revealed both communities in the logo Anseba sub region were vulnerable to the effects of climate change and variability. But the degree of vulnerability varied with the two communities. The vulnerability of the major components illustrated by the spider diagram as shown in Figure 3 presented information on which household's characteristic contribute most to the climate change variability in each community. The vulnerability spider diagram ranges between zero (least vulnerable) and 0.8 (extremely vulnerable). Accordingly, Liban was more vulnerable in terms of food, health and water components. Whereas for the other components both communities showed comparable vulnerability.

Figure 3 Vulnerability spider diagram of the major components of the LVI for Debri and Liban communities Source: Authors' computations from Field Survey (2019)

The overall livelihood indices of the major components for Debri and Liban were 0.388 and 0.450. This means that Liban households were more vulnerable than Debri households. The significance of this vulnerability as shown in Table 4 is expressed in the two-sample t-test of the livelihood components and descriptive statistical data for the major components of LVI (Table 5)

Table 4 Statistical summary of the difference in mean LVI

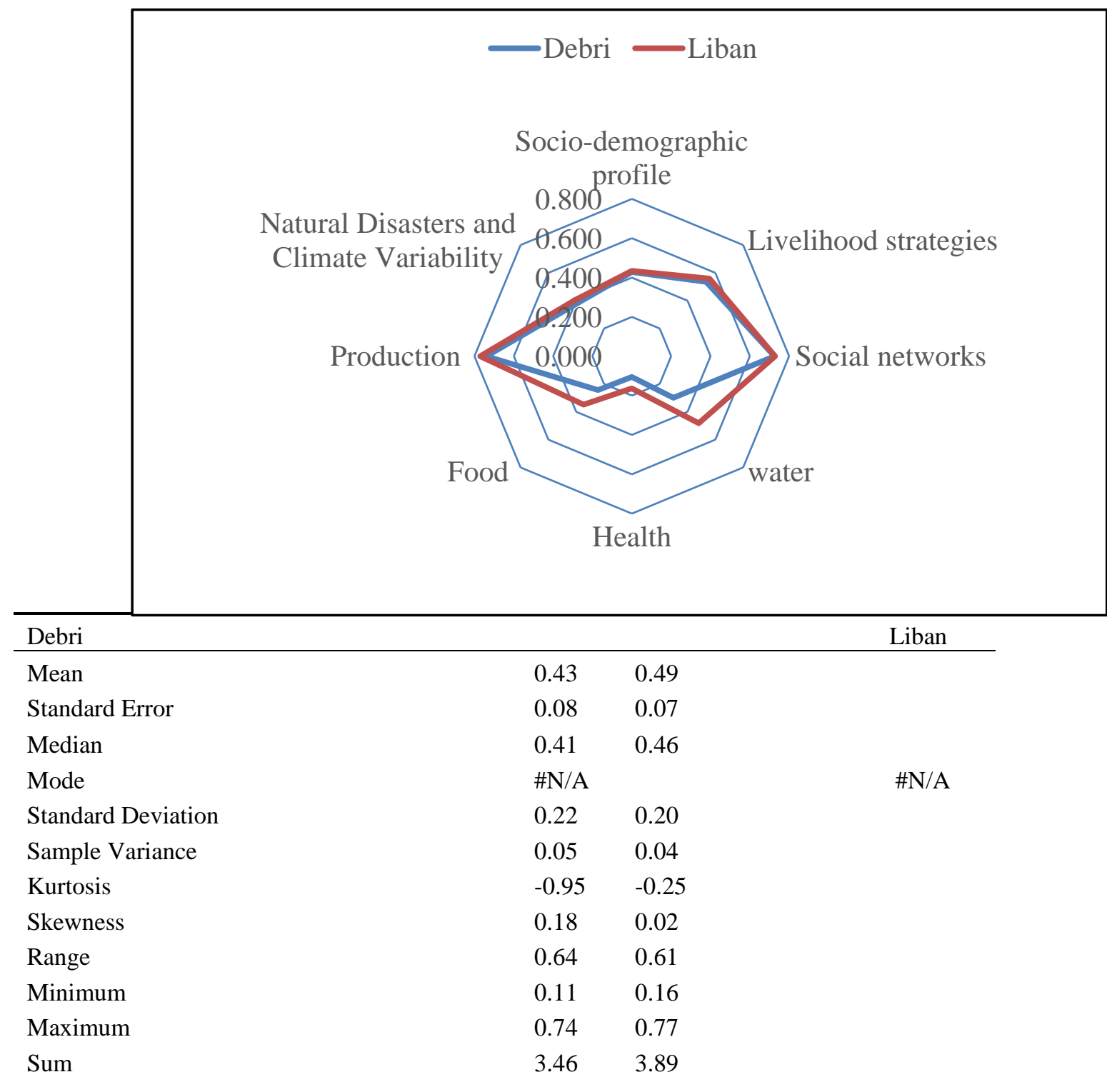

This publication is licensed under Creative Commons Attribution CC BY. 


\begin{tabular}{lll} 
Count & 8.00 & 8.00 \\
Confidence Level $(95.0 \%)$ & 0.19 & 0.17 \\
\hline
\end{tabular}

Table 5 Results of two-sample t-test of the difference in mean LVI

\begin{tabular}{llc}
\hline & Debri & Liban \\
\hline Mean & & \\
Variance & 0.43 & 0.49 \\
Observations & 0.05 & 0.04 \\
Pooled Variance & 8.00 & 8.00
\end{tabular}

\begin{tabular}{|c|c|c|c|c|}
\hline 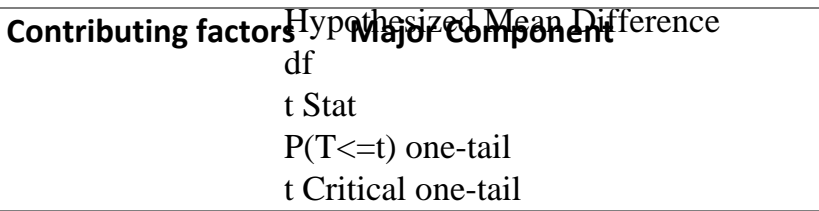 & $\begin{array}{lc}\text { Major } & 0.00 \\
\text { Component valued } & \\
-0.51 \\
0.31 \\
1.76\end{array}$ & $\begin{array}{l}\text { Number of sub } \\
\text { component per } \\
\text { major component }\end{array}$ & contrib & factor value \\
\hline $\mathrm{P}(\mathrm{T}<=\mathrm{t})$ two-tail & Liban. 62 & & Debri & Liban \\
\hline Adaptive Capacity t Critical dye-tail graphic profile & 0.432 .14 & 4 & 0.549 & 0.560 \\
\hline Livelihood strategies & 0.535 & 3 & & \\
\hline Social networks & 0.725 & 3 & & \\
\hline sensitivity & 0.299 & 5 & 0.288 & 0.396 \\
\hline Health & 0.105 & 4 & & \\
\hline Food & 0.243 & 5 & & \\
\hline Production & 0.740 & 2 & & \\
\hline $\begin{array}{l}\text { Natural Disasters and Climate } \\
\text { Variability }\end{array}$ & 0.385 & 5 & 0.385 & 0.406 \\
\hline LVI-IPCC value & & & -0.047 & -0.0609 \\
\hline
\end{tabular}

From the result of the $t$-test the stress level of Liban community $(M=0.49, \mathrm{SD}=0.20, \mathrm{n}=8)$ was hypothesized to be greater than the stress level of Debri Community $(\mathrm{M}=0.43, \mathrm{SD}=0.22, \mathrm{n}=8)$. This difference was significant, $t(14)=2.14, \mathrm{p}=0.31$ (one tail) LVIIPCC: Debri versus Liban

The LVI-IPCC analysis for the two communities reflects comparable results (Debri -0.0472, Liban -0.0609). This indicates that, in terms of climate change and variability, Liban households was more vulnerable than Debri households. The LVI-IPCC was calculated by grouping the eight major components into three categories namely Exposure, sensitivity and adaptive capacity (table 6)

\section{(Table 6) LVI-IPCC contributing factors calculation for Debri and Liban communities, Logo Anseba Eritrea}

The IPCC definition of vulnerability, which takes into account the three contributing factors of climate change and variability, is presented in the vulnerability triangle as shown in figure 4 . The value ranges from 0 (low contributing factor) and 0.6 (high contributing factor). The vulnerability triangle shows that Liban households were more exposed and sensitive to climate change and variability. 


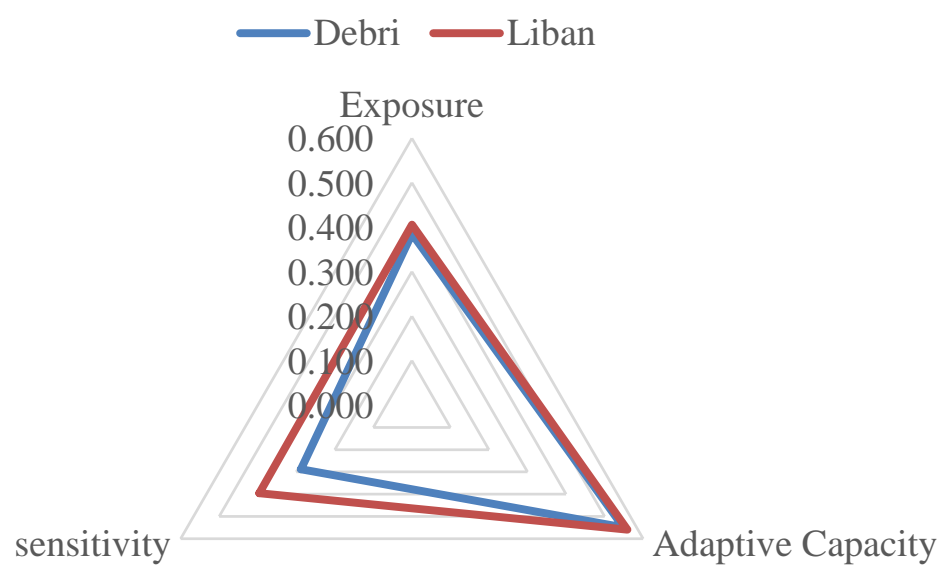

Figure 4 Vulnerability Triangle Diagram of LVI-IPCC for Debri and Liban Communities Source: Authors' computations from Field Survey (2019)

The result again showed that there was a difference between the LVI-IPCC computed for the Debri and Liban Communities (Table 6). The significance of this vulnerability as shown in Table 7 is expressed in the two-sample t-test of the livelihood components and descriptive statistical data (Table 8) for the major components of LVI

Table 7 Results of two-sample t-test of the difference in mean LVI-IPCC

\begin{tabular}{lll}
\hline & Debri & Liban \\
\hline Mean & 0.407542 & 0.453866 \\
Variance & 0.01742 & 0.008409 \\
Observations & 3 & 3 \\
Pooled Variance & 0.012915 & \\
Hypothesized Mean Difference & 0 & \\
df & 4 & \\
t Stat & -0.49924 & \\
P(T<=t) one-tail & 0.321909 & \\
t Critical one-tail & 2.131847 & \\
P(T<=t) two-tail & 0.643819 & \\
t Critical two-tail & 2.776445 & \\
\hline
\end{tabular}

From the result of the $t$-test the Liban community have high stress level of $(\mathrm{M}=0.41, \mathrm{SD}=0.09, \mathrm{n}=3)$ which was hypothesized to be greater than the stress level of Debri Community $(\mathrm{M}=0.453, \mathrm{SD}=0.13, \mathrm{n}=3)$. This difference was significant, $t(14)=2.14, \mathrm{p}=$ 0.31 (one tail)

Table 8 statistical summary results of two-sample t-test of the difference in mean LVI-IPCC

\begin{tabular}{lll}
\hline & Debri & Liban \\
\hline Mean & 0.407542 & 0.453866 \\
Standard Error & 0.076202 & 0.052944 \\
Standard Deviation & 0.131986 & 0.091701 \\
Sample Variance & 0.01742 & 0.008409 \\
Count & 3 & 3 \\
Confidence Level (95.0\%) & 0.327872 & 0.227798 \\
\hline
\end{tabular}




\section{Conclusion and Recommendation \\ Conclusion}

The vulnerability of small holder farmers to climate change in Logo Anseba sub region of Eritrea was assessed by using the livelihood vulnerability index assessment approach. The analyzed result revealed that Liban households were more vulnerable in terms of all the major components. The overall LVI calculated revealed that Liban households were found vulnerable to climate change and variability with LVI value of 0.450 as compared to Debri households with 0.388 .

The LVI-IPCC approach also indicate similar result of vulnerability to climate change in both communities It shows that households in Liban still holds greater vulnerability - 0.0609 as compared to Debri households with LVI-IPCC value of -0.047

The study underlined that climate change is affecting the subsistence agricultural communities of logo Anseba sub-region. Therefore, climate change adaptation should be an integral component of a holistic effort to build resilience of communities to the vulnerability of climate change and variability being experienced.

\section{Recommendations}

Logo Anseba sub region is one of the most vulnerable groups to the adverse effects of climate change mainly because of the low adaptive capacity and high exposure due to its semi-arid climatic condition. Hence this study provides the following recommendations. First, the local government should give some development priority in Liban community to minimize the level of sensitivity to climate change and variability. In Order to do this more projects should be planned in this community to modify the availability of water, food, health facilities and increase the agricultural extension systems. Even at the time of this study Liban households are utilize water from the dams of Debri community. Therefore, water projects should be enforced in Liban community. Second, the metrological agencies should be armed with sophisticated equipment to timely forecast about the imminent natural disasters and disseminate the information to the communities. Information could be abnormal weather conditions, floods and incidence pestilence and this is based on the empirical results that majority of the respondents in both communities said they didn't receive prior warning on impending disasters.

Finally, the LVI approach conducted in this study was done at a community level to compare vulnerability among the selected two communities in Logo Anseba sub region. Hence the result should be interpreted as restricted to this area. LVI provide a useful tool for development planners to evaluate livelihood vulnerability to climate change impacts. Thus, this approach should be exercised to conduct vulnerability assessment in Eritrea by concerned authorities in all sectors or researchers for that matter.

\section{Appendix A}

observed and minimum and maximum sub-component values for Debri and Liban communities in Logo Anseba community

Major Components Sub components

Socio-demographic

Profile

Livelihood strategy

Social networks

water index past 12 months
Dependency ratio

Percent of female-headed households

Average age of female-head of household

Percent of households where head of household has not attended school

Percent of households with family member working in a different community

Percent of households dependent solely on agriculture as a source of income

Average agricultural livelihood diversification

Average receive: give ratio

Average borrow: lend money ratio

Percent of households that have not gone to their local government for assistance in the

Percent of households reporting water conflicts

Percent of households that utilize a natural water source

Average time to water source

Percent of households that do not have a consistent water supply

Inverse of the average number of liters of water stored per household units

Debri Liban

atio

percent

$1 /$ years

percent

percent

percent

1/\#livelihood+1 0.196

ratio

ratio

percent

percent

percent

Minutes

percent

1/Liters
1.52

14

0.0218

69.5

31.8

89.5

0.196

.18

98

98

11

90

33.8

21.1

0.012
1.38

18.3

0.0214

77

43.3

65.8

0.238

1.32

1

95

80

55

64

41

0.006
Maximum Value in both villages

10

100

0.0232

100

100

100

0.33

4

1

100

100

100

30

$100 \quad 0$ 0

0

0

0

0

0.5

0

0

0

0 minimum

Value in both villages

0.0181

0.11

0.048

0.002

This publication is licensed under Creative Commons Attribution CC BY. 
Health

Food

\section{Production}

Natural Disasters and Climate Variability
Average time to health facility in min. (on minutes

foot)

Percent of households with family member with chronic illness

Percent of households where a family member percent had to miss work or school in the past 6 months due to illness

Average malaria exposure*prevention index

Percent of households dependent solely on the family farm for food

Average number of months households struggle to find food

Percent of households that do not save crops Percent of households that do not save seeds

Average Crop Diversity Index

Percent of households that use drought resistant crop varieties to adapt climate change Percentage of household facing problems related to climate change before and/or after harvesting the produce(pest/weed/disease)

Percent of households that did not receive a warning about the pending natural disasters since last 6years Percent of households with an injury or death as a result of flood or drought since last 6years

Mean standard deviation of monthly average of average maximum daily temperature (2009. 2018)

Mean standard deviation of monthly average of average minimum daily temperature (20092018)

Mean standard deviation of monthly average precipitation (2009-2018)

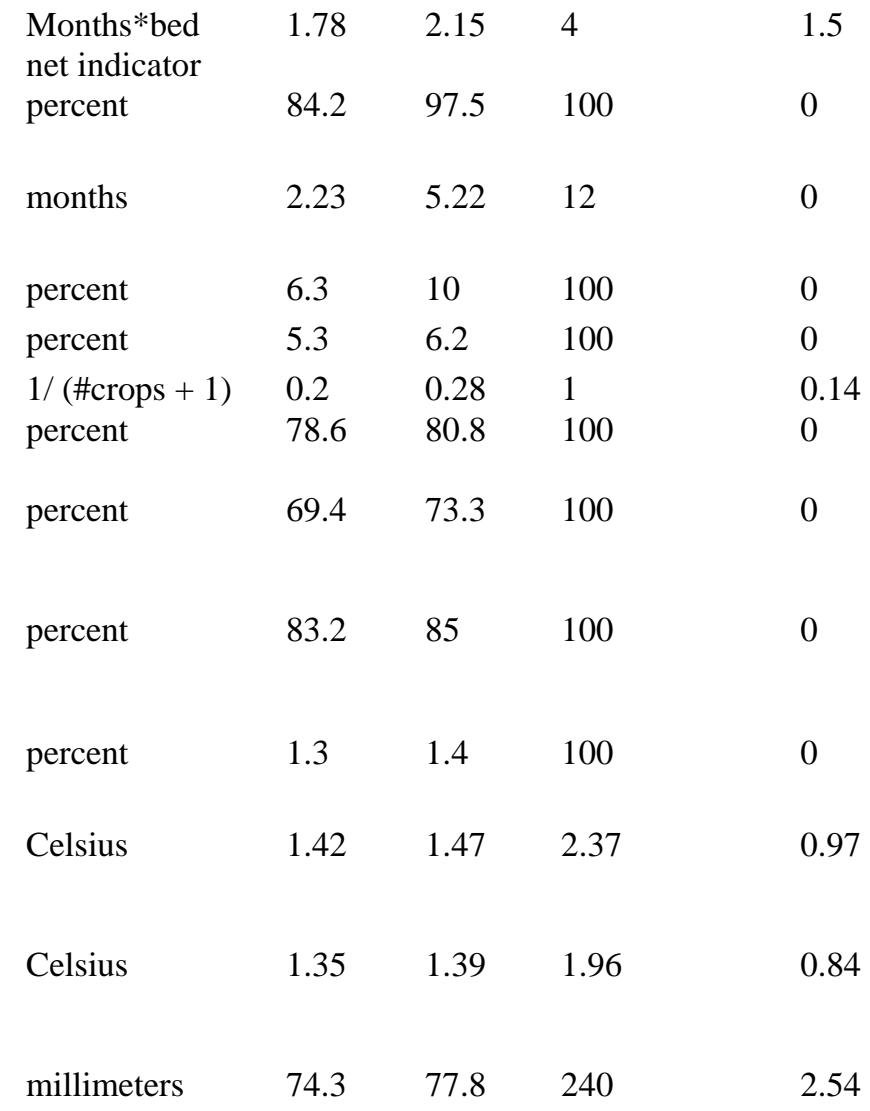

60

0

0

1.5

0

0.14

0

.97

.84

\section{Appendix B}

LVI-IPCC contributing factors calculation for Debri and Liban communities, Logo Anseba Eritrea

Contributing factors

Debri

0.385

0.549

0.288

$\mathbf{- 0 . 0 4 7 1 8 0 0 3 6}$

LVI-IPCC value
Liban

0.406

0.560

0.396 
Appendix C

Major Sub components

Components

Natural
Disasters and
Climate
Variability

(NDCV)

\section{NDCV1}

Percent of households that

did not receive a warning

about the pending natural

disasters since last 6years

Percent of households with an injury or death as a result of flood or drought since last 6years NDCV 2

Mean standard deviation of monthly average of average maximum daily temperature (2009-2018) NDCV 3

Mean standard deviation of monthly average of average minimum daily temperature (2009-2018) NDCV 4

Mean standard deviation of monthly average precipitation (2009-2018)
Liban
Maximum Value
in both villages

85

100

$1.4 \quad 100$

0

0.092

$1.47 \quad 2.37$

0.97

0.357

$1.39 \quad 1.96$

0.84

0.491

$77.8 \quad 240$

2.54

0.317

\section{NDCV 5}

Step 1 (repeat for NDCV 2, NDCV 3......) Index IDCV $_{\text {Liban }}=\frac{\mathbf{8 5 - 0}}{\mathbf{1 0 0 - 0}}=\mathbf{8 5}$

Step 2 (repeat for $\mathrm{NDCV} 2, \mathrm{NDCV} 3 \ldots$ ) $\quad \boldsymbol{N D C V}_{\text {Liban }}=\frac{\sum_{i=1}^{n} \text { index }_{\text {di }}}{n}=\frac{\text { NDCV1 }+N D C V 2+N D C V 3+N D C V 4+N D C V \%}{\mathbf{5}}=$ $\frac{0.917+0.092+0.357+0.491+0.317}{5}=\mathbf{0 . 4 3 5}$

$\begin{array}{llllll}\text { Step } & \text { (repeat for } & \text { NDCV } & \text { NDCV } & 3 \ldots \text { ) }\end{array}$ $L V I_{\text {Liban }}=\frac{\sum_{n=1}^{n} W_{M_{i}} M d_{i}}{\sum_{i=1}^{8} W M_{i}}=$

Contributing factors Major Component

Socio-demographic profile

Livelihood strategies

Social networks

sensitivity

water

Health

Food

Production

Exposure

LVI-IPCC value

$\frac{(4)(0.435)+(3)(0.738)+(3)(0.721)+(5)(0.461)+(4)(0.164)+(5)(0.435)+(2)(0.730)}{4+3+3+5+4+5+5+2}=0.465$

\section{Major Component Value}

Liban

0.435

0.558

0.728

0.481

0.164

0.347

0.771

$0.406 \quad 5$

Number of sub contributing factor value component per major component

4
3
3
5
4
5
2
5

Liban

0.560

0.396

0.406

$-0.0609$

\section{Appendix D}

Step 1 repeat all steps in Appendix B

Step 2 (repeat for all contributing factors): Adapive capacity Liban $=\frac{\sum_{i=1}^{n} W_{M_{i}} M_{d_{i}}}{\sum_{i=1}^{n} W_{M_{i}}}=\frac{(4)(0.435)+(3)(0.558)+(3)(0.728)}{4+3+3}=$ 0.560

step 3 (repeat for both communities) : LVI - IPCC $=\left(\mathbf{e}_{\text {Liban }}-\mathbf{a}_{\text {Liban }}\right) * S_{\text {Liban }}=(0.406-0.560) * 0.396=-0.0609$ 


\section{REFERENCES}

[1] 1. Scholze, M., et al., A climate-change risk analysis for world ecosystems. Proceedings of the National Academy of Sciences, 2006. 103(35): p. 13116-13120.

[2] 2. Dankelman, I., Introduction: exploring gender, environment and climate change, in Gender and climate change: An introduction. 2012, Routledge. p. 29-46.

[3] 3. Morton, J.F., The impact of climate change on smallholder and subsistence agriculture. Proceedings of the national academy of sciences, 2007. 104(50): $\mathrm{p}$ 19680-19685.

[4] 4. ReidaR almås, H.B.a.m.g.R.-F., Agriculture_and_Climate_Change. nt. Jrnl. of Soc. of Agr. \& Food,, , , 2011. Vol. 18(No. 3): p. pp. 162-166.

[5] 5. o'Brien, K., et al., Mapping vulnerability to multiple stressors: climate change and globalization in India. Global environmental change, 2004. 14(4): p. 303313.

[6] 6. Ciais, P., et al., Climate change 2013: the physical science basis. Contribution of Working Group I to the Fifth Assessment Report of the Intergovernmental Panel on Climate Change. K., Tignor, M., Allen, SK, Boschung, J., Nauels, A., Xia, Y., Bex, V., Midgley, PM, Eds, 2013.

[7] 7. Stat, O., OECD-FAO agricultural outlook 2016-2025 data. 2016.

[8] 8. Woodward, A., et al., Climate change and health: on the latest IPCC report. The Lancet, 2014. 383(9924): p. 1185-1189.

[9] 9. IPCC, T., IPCC Third Assessment Report-Climate Change 2001. Climate Change, 2001.

[10] 10. McSweeney, C. and R. Jones, Selecting members of the 'QUMP'perturbed-physics ensemble for use with PRECIS. Met Office Hadley Centre, UK, 2010.9.

[11] 11. Zeremariam, T.K. and N. Quinn, An evaluation of environmental impact assessment in Eritrea. Impact Assessment and Project Appraisal, 2007. 25(1): p. 5363.

[12] 12. Backes, G., et al., High genetic diversity revealed in barley (Hordeum vulgare) collected from small-scale farmer's fields in Eritrea. Genetic resources and crop evolution, 2009. 56(1): p. 85-97.

[13] 13. Eritrea, S.o., National Agriculture Programme Programme Design Report.

[14] 14. MOLWE, <Vulnerability Assessment Report -2005.pdf>. 2005.

[15] 15. Ghebru, B. and T. Mehari, Innovative Agricultural Approaches of Promoting Food Security in Eritrea: Trends, Challenges and Opportunities for Growth: Proceedings of the Workshop of the Association of Eritreans in Agricultural Sciences (AEAS). 2007, Geographica Bernensia.

[16] 16. MINISTRY OF LAND, W.A.E., ERITREA'S SECOND NATIONAL COMMUNICATION (SNC). 2012. 2.

[17] 17. Furlow, J., et al., Building resilience to climate change through development assistance: USAID's climate adaptation program. Climatic change, 2011. 108(3): p. 411

[18] 18. Hahn, M.B., A.M. Riederer, and S.O. Foster, The Livelihood Vulnerability Index: A pragmatic approach to assessing risks from climate variability and change-A case study in Mozambique. Global environmental change, 2009. 19(1): p. 74-88.

[19] 19. Smit, B. and O. Pilifosova, Adaptation to climate change in the context of sustainable development and equity. Sustainable Development, 2003. 8(9): p. 9.

[20] 20. Smit, B. and O. Pilifosova, From adaptation to adaptive capacity and vulnerability reduction, in Climate change, adaptive capacity and development. 2003, World Scientific. p. 9-28.

[21] 21. Kelly, P.M. and W.N. Adger, Assessing vulnerability to climate change and facilitating adaptation. 1999: Centre for Social and Economic Research on the Global Environment.

[22] 22. Kelly, P.M. and W.N. Adger, Theory and practice in assessing vulnerability to climate change andFacilitating adaptation. Climatic change, 2000. 47(4): p. 325-352

[23] 23. Yemane, B., Y. Berhane, and K.S. Reddy, Ethnobotanical Study of Medicinal Plants in Sub region Logo Anseba, Region Gash Barka, Eritrea. J Pharm Biol Sci, 2016. 11: p. 63-73.

[24] 24. Simpson, I.R., et al., Causes of change in Northern Hemisphere winter meridional winds and regional hydroclimate. Nature Climate Change, 2016. 6(1): $p$ 65-70.

\section{AUTHORS}

First Author - Dawit Tesfai, Tongji University, UN Environment-Tongji Institute of Environment for Sustainable Development (IESD): College of Environmental Science and Engineering. Tongji University, Shanghai 200092, P.R. China., dawates6268@gmail.com, , Tel +8613262204078,+291-7-179126

Second Author - Zhang Jing, Tongji University, UN Environment-Tongji Institute of Environment for Sustainable Development (IESD): College of Environmental Science and Engineering. Tongji University, Shanghai 200092, P.R. China.

Correspondence Author - Zhang Jing Email: jingzhang@ tongji.edu.cn, Tel +8618616305862 